\author{
Przemysław Paciorek*1,2, Karolina Obońska3* (D), Wojciech Skrzyński², Jakub Ratajczak ${ }^{3,4}$ \\ ${ }^{1}$ Department of Family Medicine, Nicolaus Copernicus University, Collegium Medicum in Bydgoszcz, Poland \\ 2Emergency Medical Services in Bydgoszcz \\ ${ }^{3}$ Department of Cardiology and Internal Medicine, Nicolaus Copernicus University, Collegium Medicum in Bydgoszcz, Poland \\ ${ }^{4}$ Department of Health Promotion, Nicolaus Copernicus University, Collegium Medicum in Bydgoszcz, Poland \\ *Equally contributing authors
}

\title{
Observational, retrospective study evaluating the temporal variability of out-of-hospital cardiac arrests (OHCA) in the district of Bydgoszcz in a 24-month period
}

\section{Corresponding author:}

Karolina Obońska, Department of Cardiology and Internal Medicine, Nicolaus Copernicus University, Collegium Medicum in Bydgoszcz; Maria Curie Sklodowska 9 Street; 85-094, Poland,

e-mail: k.obonska@cm.umk.pl
Medical Research Journal 2021; Volume 6. Number 3, 217-223 10.5603/MRJ.a2021.0043 Copyright (c) 2021 Via Medica ISSN 2451-2591 e-ISSN 2451-4101

\begin{abstract}
Introduction: The incidence of out-of-hospital cardiac arrests (OHCA) varies periodically. The aim of our study was to assess the temporal variability of $\mathrm{OHCA}$ occurrence in adult population of Bydgoszcz district. Material and methods: A retrospective analysis of 782 cases of OHCA, which occurred between January $1^{\text {st }}, 2018$, and December $31^{\text {st }}, 2019$, was performed. The temporal variability of OHCA occurrence was assessed during the day (within twenty-four 1-hour periods and four 6-hour time intervals), weeks, months, and seasons of the year.

Results: The incidence of OHCA in the analyzed population was 84 per 100,000 inhabitants/year. The highest incidence of OHCA was observed between 08:00 and 08:59 and between 15:00 and 15:59. The lowest number of OHCA occurred at night $(n=84 ; 10.7 \% ; p<0.001)$. During the week, the lowest number of OHCA was noted on Saturday (12.4\%) and the highest on Monday (16.5\%), with no significant differences between days. The highest incidence of OHCA was observed in winter and the lowest in summer [225 (28.8\%) vs. 171 (21.9\%), $p=0.006$ ]. December was the month with the highest number of OHCA cases, and July the lowest.

Conclusions: The present analysis confirms that the occurrence of OHCA demonstrates circadian, monthly, and seasonal rhythm. The highest incidence of OHCA was in the morning and afternoon, and in winter, especially in December. The lowest occurrence of OHCA was at night and in the summer, particularly in July. There was a weekly pattern with the highest occurrence of OHCA on Mondays; however' no significant differences between weekdays were achieved.
\end{abstract}

Key words: acute coronary syndrome, chronobiology, circadian rhythm, out-of-hospital cardiac arrest, resuscitation

Med Res J 2021; 6 (3): 217-223

\section{Introduction}

Out-of-hospital cardiac arrest $(\mathrm{OHCA})$ remains a significant issue worldwide. It is defined as the loss of functional cardiac mechanical activity in association with an absence of systemic circulation, occurring outside of hospital [1]. OHCA is the leading cause of death in developed countries [1, 2]. The average occurrence of OHCA in adults worldwide is $95.9 / 100,000$ per year, while European incidence varies according to sources from 16 to $119 / 100,000$ per year [2]. In Poland, the estimated total number of OHCA is 15200 per year [3]. The predominant cause of $\mathrm{OHCA}$ is coronary artery disease [1]. According to the analysis by Berdowski at al., the global average incidence of $\mathrm{OHCA}$ of presumed cardiac cause was 55 adult per 100,000 person-years [4]. Large 
differences in reported rates may result from the use of different OHCA definitions, investigated populations, differences in Emergency Medical Services (EMS) in various regions, as well as research methodology. Regardless of the reported number, the survival rate after OHCA is frighteningly low with the average at $7 \%$ in the adult population [4].

Circadian rhythms - well established in humans - affect not only hormone, cytokine, and fibrinogen changes, but also influence endothelial function, vascular tone, and blood pressure [5]. That, in turn, translates into occurrence of acute coronary syndromes throughout the day [6]. Furthermore, it was demonstrated that the incidence of OHCA of cardiac etiology shows not only daily, but also weekly, monthly, and seasonal variation [7]. OHCA due to its unexpected nature and life-threatening features remains at the center of interest of researchers and healthcare professionals. A better understanding this complex phenomenon will enable more effective assistance to our patients and improve long-term outcomes. Hence, the need for further research in this area.

The aim of our study was to assess the temporal variability of OHCA occurrence in the adult population of Bydgoszcz district.

\section{Material and methods}

A retrospective analysis of dispatched cards from EMS in Bydgoszcz district between January $1^{\text {st }}, 2018$, and December $31^{\text {st }}, 2019$, was performed. Dispatch cards were compatible with the Utstein template. Bydgoszcz district includes the city of Bydgoszcz and surrounding towns and occupies $1395 \mathrm{~km}^{2}$ [8]. During the study period, it was inhibited by approximately 470000 citizens $[8,9]$. The district includes $176 \mathrm{~km}^{2}$ of urban areas inhibited by $75.5 \%$ of the population and $1219 \mathrm{~km}^{2}$ of suburban areas.

An OHCA was defined as a sudden and unexpected event leading to a cardiac arrest. The mechanism of cardiac arrest was determined based on the first recorded heart rhythm: shockable (ventricular fibrillation [VF] or ventricular tachycardia [VT]) or non-shockable (asystole or pulseless electrical activity [PEA]). Patients with $\mathrm{OHCA}$ due to trauma, younger than 18 years of age and with late signs of death (i.e., rigor mortis, decomposition) were excluded from the analysis.

To maintain comparability with other studies a similar pattern of division was used to analyze the OHCA occurrence. Circadian rhythm was investigated within twenty-four 1-hour periods and four 6-hour time intervals: night (0:00- 5:59), morning (6:00-11:59), afternoon (12:00-17:59), and evening (18:00-23:59). The weekly variation was analyzed for days of the week and monthly variation was analyzed for individual months. The sea- sons were defined as: spring (March, April, May), summer (June, July, August), autumn (September, October, November), and winter (December, January, February).

The present study was approved by the Ethics Committee of the Nicolaus Copernicus University in Torun, Collegium Medicum in Bydgoszcz and was conducted in accordance with Declaration of Helsinki and Good Clinical Practice guidelines.

\section{Statistical analysis}

IBM SPSS Statistic software version 27 was used to perform the statistical analysis. The data distribution was checked using the Shapiro-Wilk test. Categorical variables were presented as counts and percentages. Continuous variables were reported as means with standard deviation (SD) or medians with interquartile range (IQR). The distribution of OHCA cases was generally non-normal and the differences between medians were small even when statistically significant. Therefore, it was decided to present the data as percentages to better visualize observed differences. The differences between variables were tested using the Mann-Whitney test or the Kruskal-Wallis test, as appropriate. Two-sided p-value $<0.05$ was applied for statistical significance.

\section{Results}

\section{General characteristic}

There were 782 cases of OHCA included in the present analysis. The incidence of $\mathrm{OHCA}$ in the present population was 84 per 100,000 inhabitants per year. Among the enrolled patients, the majority were men $(63.6 \%, p<0.001)$. The mean age of patients was $69.2 \pm 14.2$ years. Non-shockable rhythm as the first recorded rhythm was present in $79 \%$ cases. The majority of OHCA events occurred in the urban area $(84.5 \%, p<0.001)$. Baseline characteristics of the study population is presented in Table 1. The higher incidence of $\mathrm{OHCA}$ was observed in the population $>60$ years of age $(p<0.001)$ (Fig.1).

\section{Circadian variation of OHCA}

The highest incidence of OHCA was observed between 08:00-08:59 and then between 15:00-15:59 (Fig. 2). The fewest events of OHCA were observed during the night between 01:00-04:59 (Fig. 2). When analyzing 6-hours intervals (Fig. 3), the lowest number of OHCA occurred at night ( $n=84 ; 10.7 \% ; p<0.001)$. Numerically, the highest incidence of OHCA was registered in the afternoon ( $n=254 ; 32.5 \%)$. However, there were no significant differences between the number of OHCA in the morning ( $n=239 ; 30.6 \%)$, afternoon $(n=254$; $32.5 \%)$, and evening intervals $(n=205,26.2 \%)$ (Fig. 3). 
Table 1. Baseline characteristics of the study population

\begin{tabular}{lc}
\hline Variable & Study population \\
\hline Number of cases & 782 \\
Mean age [years] & $69.2 \pm 14.8$ \\
Female & $36.4 \%$ \\
Initial rhythm & \\
$\quad$ VF/VT & $21 \%$ \\
$\quad$ Asystole/PEA & $79 \%$ \\
Location & \\
$\quad$ Urban & \\
$\quad$ Suburban & $84.5 \%$ \\
\hline
\end{tabular}

\section{Weekly variation of $\mathrm{OHCA}$}

The lowest number of OHCA was noted on Saturday $(n=97,12.4 \%)$ and the highest on Monday $(n=129$, 16.5\%) (Fig. 4). However, no significant differences between particular days regarding the number of $\mathrm{OHCA}$ events were observed.

\section{Monthly and seasonal variation of $\mathrm{OHCA}$}

Figure 5 demonstrates monthly distribution of the number of OHCA. A gradual decrease in the number of OHCA was observed from May to July, with the fewest events in the latter (July: $n=50$ ), while the highest num-

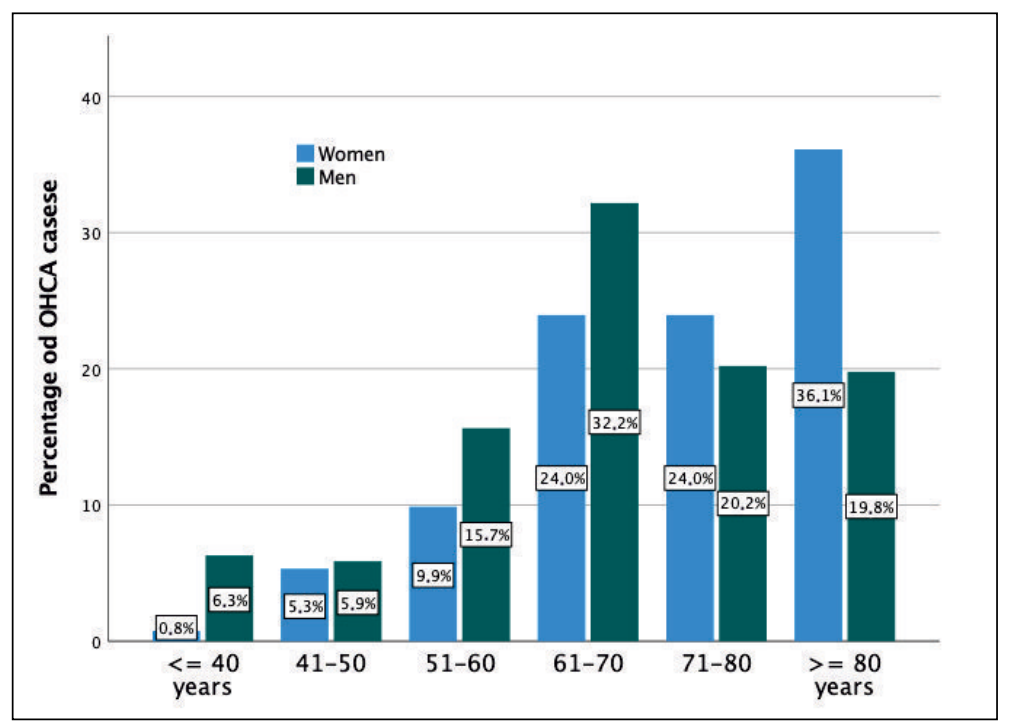

Figure 1. Distribution of out-of-hospital cardiac arrest (OHCA) in different age groups depending on gender

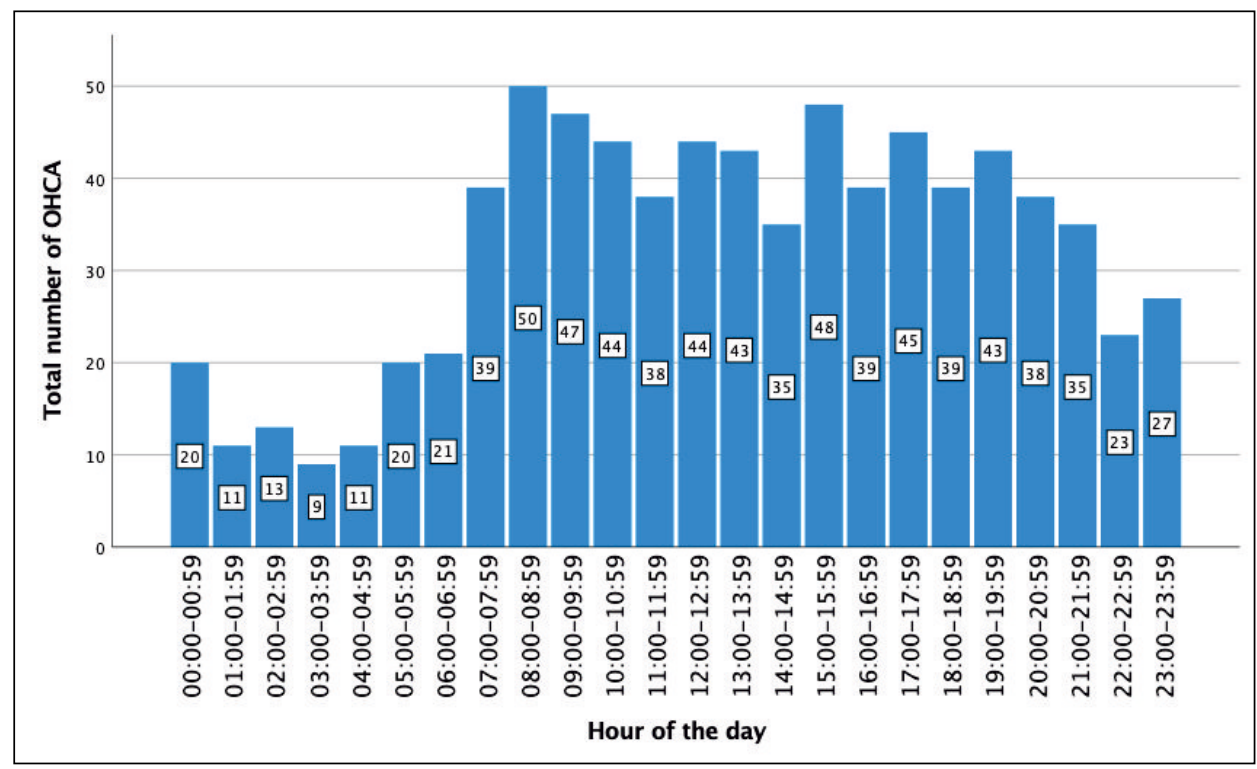

Figure 2. Circadian distribution of out-of-hospital cardiac arrest (OHCA) occurrence divided into 1-hour periods 


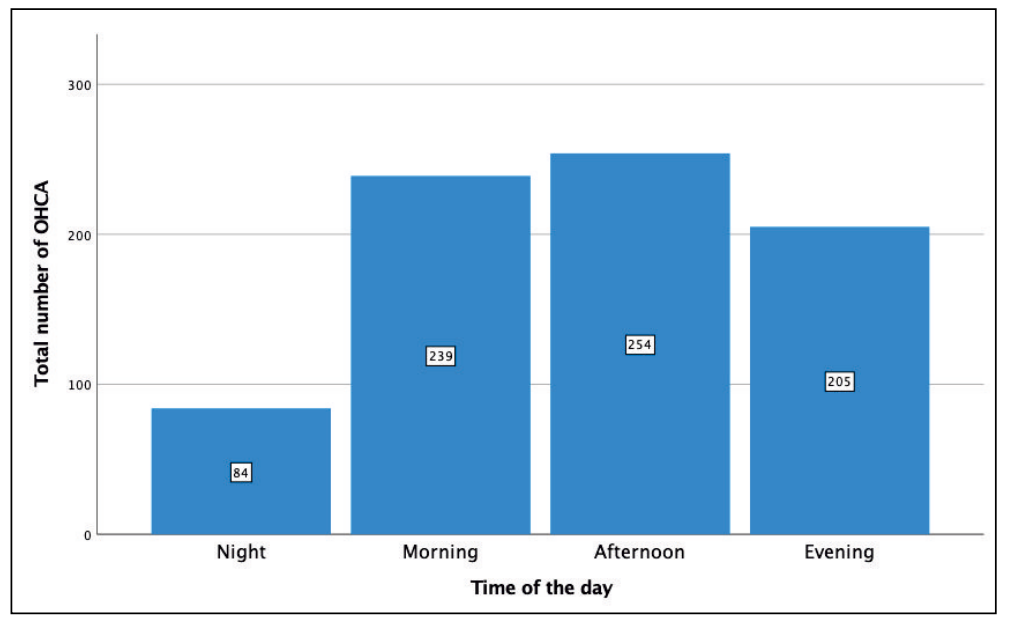

Figure 3. Number of out-of-hospital cardiac arrest (OHCA) in 6-hour intervals. Night vs. Morning: $p<0.001$; Night vs. Afternoon: $p<0.001$; Night vs. Evening: $p<0.001$; Morning vs. Afternoon: $p=0.242$; Evening vs. Afternoon: $\mathrm{p}=0.038$; Evening vs. Morning: $\mathrm{p}=0.365$

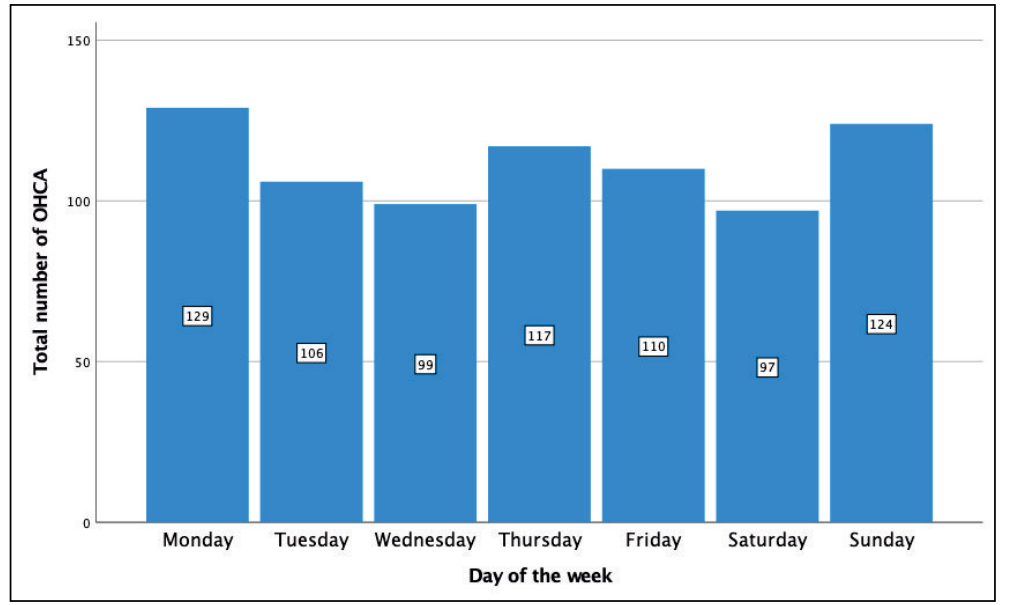

Figure 4. Distribution of out-of-hospital cardiac arrest $(\mathrm{OHCA})$ events in subsequent days of week $(p=0.095)$

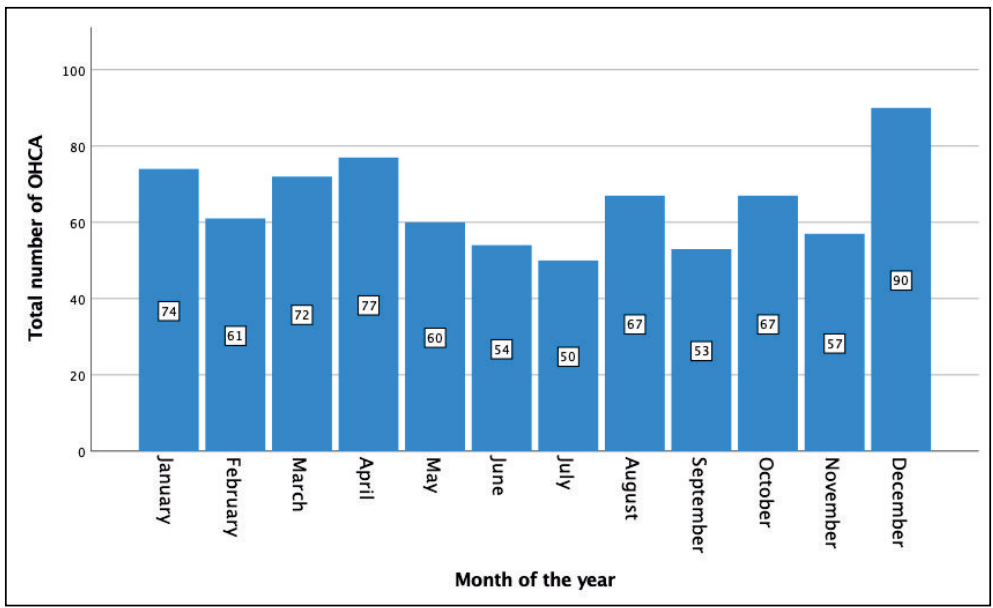

Figure 5. Distribution of out-of-hospital cardiac arrest (OHCA) events in subsequent months of the year $(p=0.52)$ 


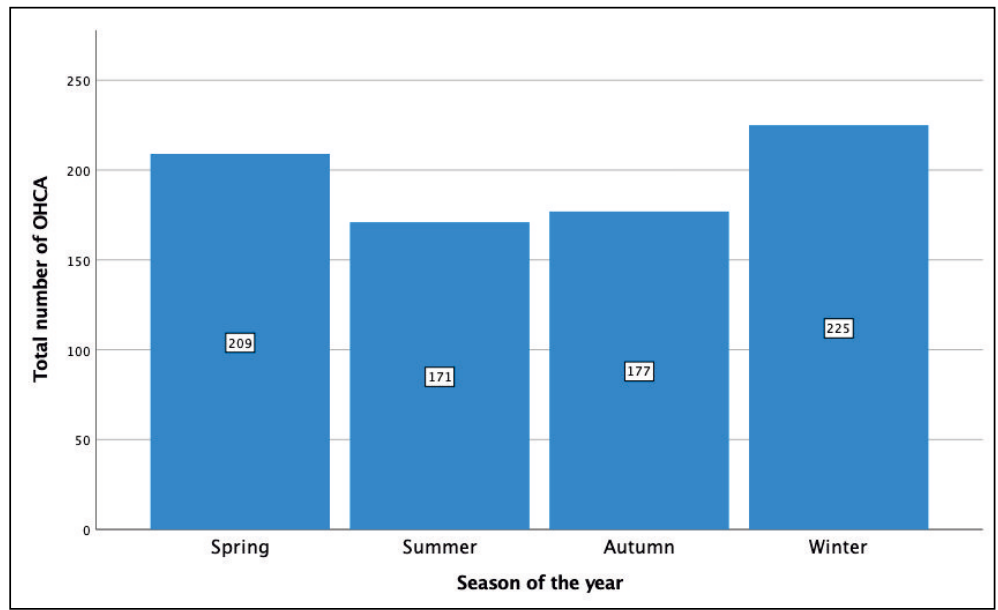

Figure 6. Seasonal distribution of out-of-hospital cardiac arrest (OHCA) events

ber of OHCA cases was registered in December [July vs. December: 50 (6.4\%) vs. 90 (11.5\%), $p=0.002$ ]. The variability in subsequent months, according to number of OHCA, was statistically insignificant $(p=0.52)$.

Considering the seasons of the year, we observed different results. There were significant seasonal differences between number of OHCA in the spring vs. summer [209 (26.7\%) vs. 171 (21.9\%), p = 0.021), autumn vs. winter [177 (22.6\%) vs. $225(28.8 \%), p=0.047$ ], and summer vs. winter [171 (21.9\%) vs. 225 (28.8\%), $p=0.006$ ) (Fig. 6). No significant difference in the number of $\mathrm{OHCA}$ events was observed between spring and winter [209 (26.7\%) vs. 225 (28.8\%), p = 0.645].

\section{Discussion}

Our study evaluating temporal variability of OHCA confirmed circadian rhythm of OHCA incidence, as well as monthly and seasonal patterns. To the best of our knowledge, it is the first study investigating temporal variation of $\mathrm{OHCA}$ conducted in the Bydgoszcz district.

The incidence of OHCA in our study was $84 / 100,000$ inhabitants per year, which corresponds to the European indicators within the range 16$119 / 100,000$ inhabitants [2]. The rate in our study is lower than demonstrated by Szczerbinski 156/100,000 [10, 11] and Gach 170/100,000 [3]. However, the population analyzed by Gach [3] was older, and it has been demonstrated that the number of OHCA increases with age.

The circadian rhythm of OHCA was associated with the lowest number of events at night. Our results are consistent with other studies in this regard $[3,7,10$, 12-14]. The highest incidence of OHCA in our study was noted in the morning (08:00-08:59) and in the afternoon (15:00-15:59). Similar results were demonstrated in numerous studies [15-20], where two-peak occurrence curve was shown. However, the afternoon peak in the mentioned studies was later (16:00-20:00) in comparison to our result [15-20]. Other reports presented three peaks of OHCA occurrence: morning (08:00-10:59), afternoon (14:00-15:59), and evening peak (18:00-21:59) [10, 21]. Morning increase in the incidence of OHCA is associated with an increased incidence of acute coronary syndromes during this time. These, in turn, are the most common causes of cardiac arrest and occur as a result of diurnal changes in blood pressure, vascular tone, heart rate, endothelial function, platelet aggregability, and catecholamines [5, 10, 14, 22-24]. The authors agree that the early morning peak of OHCA may be related to the fact that these arrests occurred without witnesses and patients were found by family members in the morning or after returning home from work in the afternoon [10,14]. Although, in our study the analysis of witnessed and non-witnessed OHCA was not performed.

When analyzing individual days of the week, the highest number of OHCA was recorded on Monday, and the lowest on Saturday. Although, the weekly variability did not reach statistical significance in our study. A similar distribution with the Monday peak in OHCA incidence was demonstrated by Herlitz et al. [7] in the Swedish population, Naknishi et al. [15] among the Japanese, and Ong et al. [16] in the population of Singapore. Contrary to our analysis, Brooks et al. [17] found the highest incidence of OHCA on Saturdays, while Allegra et al. [25] found both Monday and Saturday with the highest occurrence of OHCAs. Another analysis concerning the Polish subpopulation from the Opole district showed an increased frequency of OHCA on Saturdays, Sundays, and Mondays [10]. However, in a long-term follow-up of 13 years, Szczerbinski et al. [12] demonstrated the highest frequency of sudden cardiac arrest on Mondays. A possible explanation for the Monday peak in the OHCA occurrence is related to human behavior, work patterns, and the stress level 
[16]. A similar pattern has previously been shown for the incidence of myocardial infarctions [26, 27].

The incidence of OHCA also shows seasonal variability, with a significantly greater number of events in winter and the lowest in summer. According to monthly variability, the highest occurrence of OHCA was noted in December, and the lowest in July. Our observations are in line with the results of other researchers' [3, 7, $12,15,17,25]$. Meanwhile, observations from Singapore [16] did not confirm the seasonal variability in the incidence of OHCA. However, the equatorial climate of Singapore has a constant temperature and weather throughout the year [16]. Meanwhile, studies conducted in a moderate climate, where we observe seasonal changes in temperature, air pressure, and precipitation, clearly indicate the influence of atmospheric conditions on the occurrence of OHCA. A possible explanation is the effect of low temperature on arterial blood pressure [16, 28], arterial spasm, platelet and red blood cells count, blood viscosity $[16,29]$, and serum cholesterol levels [16, 30]. Low temperature affects hemodynamic processes, including an increase in systemic vascular resistance and oxygen consumption by myocardium [16, 31].

The last two years have unexpectedly brought another threat - related to the severe acute respiratory syndrome coronavirus 2 (SARS-CoV-2) pandemic. As reported by the latest registers from around the world, the incidence of OHCA increased significantly during the pandemic [32, 34-39]. Moreover, performed meta-analyzes demonstrated that not only the incidence but also mortality following OHCA were higher during the COVID-19 pandemic [32, 33, 40]. Borkowska et al. [40] explained that reduced survival rate after OHCA in suspected or diagnosed COVID-19 patients was probably due to the lower rate of shockable rhythms in COVID-19 patients [32, 40]. Further studies on the impact of COVID-19 on the OHCA occurrence, taking into account previously demonstrated risk factors and treatments, are necessary [41-45].

Cardiac arrest is a complex process that requires a prompt and professional action to restore a haemodynamically efficient heart rhythm, followed by continued treatment for the causes of the condition [46, 47]. Hence, further intensive research on this phenomenon is necessary to improve outcomes after OHCA. The COVID-19 pandemic has revealed how much remains to be done.

\section{Conclusions}

The present analysis confirms that the occurrence of OHCA demonstrates circadian, monthly, and seasonal rhythm. The highest incidence of OHCA was in the early morning and afternoon and in winter, especially in December. The lowest occurrence of OHCA was at night and in summer, particularly in July. There was a weekly pattern with the highest occurrence of OHCA on Mondays; however, no significant differences between days of the week were achieved.

Limitations: The present study has several limitations.

Firstly, our study is a retrospective analysis which makes it difficult or even sometimes impossible to recover some data. Secondly, the analyzed period covered only two years and a longer follow-up would certainly be more reliable. Third, the collected data concerned only the district of Bydgoszcz and larger scale studies are necessary.

\section{Conflict of interest: None.}

\section{References}

1. Myat A, Song KJ, Rea T. Out-of-hospital cardiac arrest: current concepts. Lancet. 2018; 391(10124): 970-979, doi: 10.1016/S01406736(18)30472-0, indexed in Pubmed: 29536861.

2. Porzer M, Mrazkova E, Homza M, et al. Out-of-hospital cardiac arrest. Biomed Pap Med Fac Univ Palacky Olomouc Czech Repub. 2017; 161(4): 348-353, doi: 10.5507/bp.2017.054, indexed in Pubmed: 29235577.

3. Gach D, Nowak JU, Krzych ŁJ. Epidemiology of out-of-hospital cardiac arrest in the Bielsko-Biala district: a 12-month analysis. Kardiol Pol. 2016; 74(10): 1180-1187, doi: 10.5603/KP.a2016.0086, indexed in Pubmed: 27221961

4. Berdowski J, Berg RA, Tijssen JGP, et al. Global incidences of out-of-hospital cardiac arrest and survival rates: Systematic review of 67 prospective studies. Resuscitation. 2010; 81(11): 1479-1487, doi: 10.1016/j.resuscitation.2010.08.006, indexed in Pubmed: 20828914

5. Rudic RD. Time is of the essence: vascular implications of the circadian clock. Circulation. 2009; 120(17): 1714-1721, doi: 10.1161/CIRCULATIONAHA.109.853002, indexed in Pubmed: 19858424

6. Kubica A, Szczerbiński S, Kieszkowska M, et al. Wpływ czynników klimatycznych i chronologicznych na występowanie ostrych incydentów chorobowych. (The influence of climatic and chronological factors on the occurrence of acute disease events). Folia Cardiologica 2014; 9. 2014; 9(3): 263-266

7. Herlitz J, Eek M, Holmberg M, et al. Diurnal, weekly and seasonal rhythm of out of hospital cardiac arrest in Sweden. Resuscitation. 2002; 54(2): 133-138, doi: 10.1016/s0300-9572(02)00097-7, indexed in Pubmed: 12161292

8. Biuletyn Informacji Publicznej. Starostwo Powiatowe w Bydgoszczy. https://bip.powiat.bydgoski.pl/?c=17

9. Raport o stanie Miasta Bydgoszczy za 2018r. https://bip.um.bydgoszcz.pl/binary/raport\%20za\%202018_tcm30-255310.pdf

10. Szczerbinski S, Ratajczak J, Lach $P$ et al. Epidemiology and chronobiology of out-of-hospital cardiac arrest in a subpopulation of southern Poland: A two-year observation. Cardiol J. 2020; 27(1): 16-24, doi: 10.5603/CJ.a2018.0025, indexed in Pubmed: 29611174.

11. Szczerbiński S. Observational, retrospective analysis of the circadian variability of out-of-hospital cardiac arrest within days of the week. Medical Research Journal. 2020; 5(2): 68-71, doi: 10.5603/mrj. a2020.0020

12. Szczerbiński S, Ratajczak J, Jasiewicz M, et al. Observational analysiS of out-of-hospital Cardiac Arrest occurRence and temporal variability patterns in subpopulation of southern POLand from 2006 to 2018: OSCAR-POL registry. Cardiol J. 2021 [Epub ahead of print], doi: 10.5603/CJ.a2021.0060, indexed in Pubmed: 34312830.

13. Pleskot M, Hazukova R, Stritecka $\mathrm{IH}$, et al. The highest incidence of out-of-hospital cardiac arrest during a circadian period in survivors. Int Heart J. 2008; 49(2): 183-192, doi: 10.1536/ihj.49.183, indexed in Pubmed: 18475018 
14. Baert V, Vilhelm C, Escutnaire J, et al. on behalf GR-RéAC. Identification of a morning out-of-hospital cardiac arrest cluster of high-incidence: towards a chrono-preventive care strategy. J Eval Clin Pract. 2021 27(1): 84-92, doi: 10.1111/jep 13390, indexed in Pubmed: 32212234

15. Nakanishi N, Nishizawa S, Kitamura Y, et al. Circadian, weekly, and seasonal mortality variations in out-of-hospital cardiac arrest in Japan: analysis from AMI-Kyoto Multicenter Risk Study database. Am J Emerg Med. 2011; 29(9): 1037-1043, doi: 10.1016/i.ajem.2010.06.018, indexed in Pubmed: 20708890.

16. Ong MEh, Ng FSp, Yap S, et al. Temporal variation of out-of-hospital cardiac arrests in an equatorial climate. Open Access Emerg Med. 2010; 2: 37-43, doi: 10.2147/oaem.s9266, indexed in Pubmed: 27147836.

17. Brooks SC, Schmicker RH, Rea TD, et al. ROC Investigators. Out-of-hospital cardiac arrest frequency and survival: evidence for tempora variability. Resuscitation. 2010; 81(2): 175-181, doi: 10.1016/j.resuscitation.2009.10.021, indexed in Pubmed: 19942338.

18. Karlsson LIM, Wissenberg M, Fosbøl EL, et al. Diurnal variations in incidence and outcome of out-of-hospital cardiac arrest including prior comorbidity and pharmacotherapy: a nationwide study in Denmark Resuscitation. 2014; 85(9): 1161-1168, doi: 10.1016/j.resuscitation.2014.06.012, indexed in Pubmed: 24971509.

19. Lateef $F$, Ong MEH, Alfred $T$, et al. Circadian rhythm in cardiac arrest: the Singapore experience. Singapore Med J. 2008; 49(9): 719-723, indexed in Pubmed: 18830548.

20. Peckova M, Fahrenbruch CE, Cobb LA, et al. Circadian variations in the occurrence of cardiac arrests: initial and repeat episodes. Circulation. 1998; 98(1): 31-39, doi: 10.1161/01.cir.98.1.31, indexed in Pubmed: 9665057

21. Soo LH, Gray D, Young T, et al. Circadian variation in witnessed out of hospital cardiac arrest. Heart. 2000; 84(4): 370-376, doi: 10.1136/heart.84.4.370, indexed in Pubmed: 10995402.

22. Hermida RC, Ayala DE, Portaluppi F. Circadian variation of blood pressure: the basis for the chronotherapy of hypertension. Adv Drug Deliv Rev. 2007; 59(9-10): 904-922, doi: 10.1016/j.addr.2006.08.003, indexed in Pubmed: 17659807.

23. Nicolau GY, Haus E, Popescu M, et al. Circadian, weekly, and seasonal variations in cardiac mortality, blood pressure, and catecholamine excretion. Chronobiol Int. 1991; 8(2): 149-159, doi: 10.3109/07420529109059165, indexed in Pubmed: 1797411.

24. Tofler GH, Brezinski D, Schafer Al, et al. Concurrent morning increase in platelet aggregability and the risk of myocardial infarction and sudden cardiac death. N Engl J Med. 1987; 316(24): 1514-1518, doi: 10.1056/NEJM198706113162405, indexed in Pubmed: 3587281

25. Allegra JR, Cochrane DG, Allegra EM, et al. Calendar patterns in the occurrence of cardiac arrest. Am J Emerg Med. 2002; 20(6): 513-517. doi: 10.1053/ajem.2002.34799, indexed in Pubmed: 12369023

26. Witte DR, Grobbee DE, Bots ML, et al. A meta-analysis of excess cardiac mortality on Monday. Eur J Epidemiol. 2005; 20(5): 401-406, doi: 10.1007/s10654-004-8783-6, indexed in Pubmed: 16080587.

27. Willich $\mathrm{SN}$, Löwel $\mathrm{H}$, Lewis $\mathrm{M}$, et al. Weekly variation of acute myocardial infarction. Increased Monday risk in the working population. Circulation. 1994; 90(1): 87-93, doi: 10.1161/01.cir.90.1.87, indexed in Pubmed: 8026056

28. Alpérovitch A, Lacombe JM, Hanon O, et al. Relationship between blood pressure and outdoor temperature in a large sample of elderly individuals: the Three-City study. Arch Intern Med. 2009; 169(1): 75-80, doi: 10.1001/archinternmed.2008.512, indexed in Pubmed: 19139327

29. Fröhlich M, Sund M, Russ S, et al. Seasonal variations of rheological and hemostatic parameters and acute-phase reactants in young, healthy subjects. Arterioscler Thromb Vasc Biol. 1997; 17(11): 2692-2697, doi: 10.1161/01.atv.17.11.2692, indexed in Pubmed: 9409244

30. Ockene IS, Chiriboga DE, Stanek EJ, et al. Seasonal variation in serum cholesterol levels: treatment implications and possible mechanisms. Arch Intern Med. 2004; 164(8): 863-870, doi: 10.1001/archinte.164.8.863, indexed in Pubmed: 15111372
31. Wilmshurst P. Temperature and cardiovascular mortality. BMJ. 1994; 309(6961): 1029-1030, doi: 10.1136/bmj.309.6961.1029, indexed in Pubmed: 7950726.

32. Nadolny K, Szczerbiński S, Ładny J, et al. Out-of-hospital cardiac arrest and COVID-19 pandemic. Medical Research Journal. 2021; 6(2): 83-85, doi: 10.5603/mrj.2021.0029.

33. Lim ZJ, Ponnapa Reddy M, Afroz A, et al. Incidence and outcome of out-of-hospital cardiac arrests in the COVID-19 era: A systematic review and meta-analysis. Resuscitation. 2020; 157: 248-258, doi: 10.1016/j.resuscitation.2020.10.025, indexed in Pubmed: 33137418.

34. Borkowska MJ, Smereka J, Safiejko K, et al. Out-of-hospital cardiac arrest treated by emergency medical service teams during COVID-19 pandemic: A retrospective cohort study. Cardiol J. 2021; 28(1): 15-22, doi: 10.5603/CJ.a2020.0135, indexed in Pubmed: 33140396.

35. Fothergill RT, Smith AL, Wrigley F, et al. Out-of-hospital Cardiac Arrest in London during the COVID-19 pandemic. Resusc Plus. 2021; 5: 100066 , doi: 10.1016/i.resplu.2020.100066, indexed in Pubmed: 33521706.

36. Glober NK, Supples M, Faris G, et al. Out-of-hospital cardiac arrest volumes and characteristics during the COVID-19 pandemic. Am J Emerg Med. 2021 [Epub ahead of print]; 48: 191-197, doi: 10.1016/]. ajem.2021.04.072, indexed in Pubmed: 33975130.

37. Wienbergen H, Retzlaff T, Schmucker J, et al. Impact of COVID-19 pandemic on presentation and outcome of consecutive patients admitted to hospital due to ST-elevation myocardial infarction. Am J Cardiol. 2021; 151: 10-14, doi: 10.1016/j.amjcard.2021.04.011, indexed in Pubmed: 34049671.

38. Rashid Hons M, Gale Hons CP, Curzen Hons N, et al. Impact of coronavirus disease 2019 pandemic on the incidence and management of out-of-hospital Cardiac Arrest in patients presenting with acute myocardial infarction in England. J Am Heart Assoc. 2020; 9(22): e018379, doi: 10.1161/JAHA.120.018379, indexed in Pubmed: 33023348

39. Mathew S, Harrison N, Chalek AD, et al. Effects of the COVID-19 pandemic on out-of-hospital cardiac arrest care in Detroit. Am J Emerg Med. 2021; 46: 90-96, doi: 10.1016/j.ajem.2021.03.025, indexed in Pubmed: 33740572.

40. Borkowska MJ, Jaguszewski MJ, Koda M, et al. Impact of coronavirus disease 2019 on out-of-hospital Cardiac Arrest survival rate: A systematic review with meta-analysis. J Clin Med. 2021; 10(6), doi: 10.3390/jcm10061209, indexed in Pubmed: 33803944.

41. Nadolny K, Bujak K, Kucap M, et al. The Silesian registry of Out-of-Hospital Cardiac Arrest: study design and results of a three-month pilot study. Cardiol J. 2020; 27(5): 566-574, doi: 10.5603/CJ.a2018.0140, indexed in Pubmed: 30444257.

42. Kubica A. Rationale of cardiopulmonary resuscitation training as an element of multilevel educational and motivational project (MEDMOTION). Disaster and Emergency Medicine Journal. 2020; 5(2): 116-120, doi: 10.5603/demi.a2020.0017.

43. Ratajczak J, Łach P, Umińska JM, et al. Mild therapeutic hypothermia after out-of-hospital cardiac arrest: What does really matter? Cardiol J. 2021; 28(2): 293-301, doi: 10.5603/CJ.a2019.0023, indexed in Pubmed: 30799547.

44. Umińska JM, Ratajczak J, Buszko K, et al. Impact of mild therapeutic hypothermia on bioavailability of ticagrelor in patients with acute myocardial infarction after out-of-hospital cardiac arrest. Cardiol J. 2020; 27(6): 780-788, doi: 10.5603/CJ.a2019.0024, indexed in Pubmed: 30799546

45. Umińska JM, Buszko K, Ratajczak J, et al. Comparison of temperature measurements in esophagus and urinary bladder in comatose patients after cardiac arrest undergoing mild therapeutic hypothermia. Cardiol J. 2020; 27(6): 735-741, doi: 10.5603/CJ.a2018.0115, indexed in Pubmed: 30246234

46. Kubica J, Adamski P, Paciorek P, et al. Anti-aggregation therapy in patients with acute coronary syndrome - recommendations for medical emergency teams. Experts' standpoint. Kardiol Pol. 2017; 75(4): 399-408, doi: 10.5603/KP.a2017.0057, indexed in Pubmed: 28421594

47. Kubica J, Adamski P, Paciorek P, et al. Treatment of patients with acute coronary syndrome: Recommendations for medical emergency teams: Focus on antiplatelet therapies. Updated experts' standpoint. Cardiol J. 2018; 25(3): 291-300, doi: 10.5603/CJ.a2018.0042, indexed in Pubmed: 29671864. 